\title{
Microscopic and Surface Properties of K-Na Liquid Alloys
}

\author{
*I. Koirala ${ }^{1,2}$, B.P. Singh ${ }^{1}$, I.S. Jha ${ }^{3}$ \\ ${ }^{1}$ University Department of Physics, T.M. Bhagalpur University, India \\ ${ }^{2}$ Central department of physics, T.U.,Nepal \\ ${ }^{3}$ M.M.A.M. Campus, Biratnagar, Tribhuvan University, Nepal \\ * ishwar_koirala@yahoo.com
}

\begin{abstract}
The deviation from ideal mixture behavior and concentration dependent symmetry in the microscopic and surface properties of $\mathrm{K}$-Na liquid alloy is investigated within a simple statistical model. The concentration dependent of microscopic functions(concentration fluctuation in the long wavelength limit, Warren-Cowley short range order parameter) and surface properties(surface concentration and surface tension) has got special attention to show a tendency of like atom pairing in the mixture. The theoretical analysis reveals that energy parameter is temperature dependent, K-Na alloys is of weakly interacting system and $\mathrm{K}$-atoms segregates on the surface of $\mathrm{K}$-Na liquid alloys at bulk concentration of $\mathrm{Na}$.
\end{abstract}

Keywords: liquid alloy, simple statistical model, surface properties, microscopic functions

\section{INTRODUCTION}

The atomic arrangement in the liquid alloys is not spatially periodic in contrast to the case of crystalline materials, therefore it is well-recognized as important and promising area for research in physics and chemistry. Surface, structural and thermodynamic properties of mixing of the initial melt play important role in the formation of solid alloys. Thus the properties of the alloys in the melt are helpful to understand the alloying behaviour in the solid state. They can provide enormous amount of information for understanding metallurgical process and material preparation of the metal alloys. The solubility of a homogeneous solid phase is governed predominantly by the size factor, electrochemical effect and electron concentration. Experiences say that these factors cannot be used effectively to explain the alloying behaviour of liquid alloys in details. So, liquid alloys generate manifold interest for both the experimentalists [15]. and the theoreticians[6-27].

The alloying behavior of liquid alloys can be studied by the help of two distinct theories e.g. electronic theory of mixing and statistical mechanical theory of mixing. According to the first theory, a liquid alloy is assumed to consist of a system of ions and electrons. The problem, usually, in this approach is tackled through pseudo-potential theory[7] and hard sphere model[8-10]. But they cannot be used to obtain information regarding the concentration fluctuations in the long wave-length limit $[\operatorname{Scc}(0)$, an important thermodynamic function which determines the stability of alloys]. The conformal solution model[11] has been used by many theoreticians to study $\operatorname{Scc}(0)$ of different binary alloys[12,13].But this model cannot be used to study the short-range order parameters. However, in the eighty's decade of the last century soft sphere model[14] and one-component plasma theory[15] came into being for the binary liquid alloys to supplement the electronic theory of mixing. But the approach as a whole is found to be suitable for explaining mainly the electrical properties of alloys. On the other hand, the statistical mechanical theory[16-27] of mixing can be successfully used to obtain the analytical expressions for various thermodynamic and microscopic functions.

In the present work we intend to explain the alloying behavior of potassium-sodium liquid alloy on the basis of simple statistical model[19]. It is a statistical mechanical model in which the grand partition function is used to obtained analytic expressions for the conditional probabilities enumerating the occupation of two neighbouring sites by the atoms of the constituent elements in terms of the ordering energy. Thermodynamic parameters give us an idea about the stability and bonding strength of the constituent species of the alloy, whereas structural parameters provide the idea about ordering and segregating nature of the alloy. 
Some of the properties of mixing of K-Na alloys are symmetrical about equiatomic composition despite the large size difference of $\mathrm{Na}$ and $\mathrm{K}$ [1].

The outline of the paper is follows: In section 2, general formalism about the theory is presented. Section 3 deals with the result and discussion and conclusion are presented in section 4 .

\section{THEORETICAL FORMULISM}

\subsection{Microscopic functions}

The grand partition function for simple binary liquid alloys consisting of $\mathrm{N}_{\mathrm{A}}$ number of $\mathrm{A}$ atoms and $\mathrm{N}_{\mathrm{B}}$ number of B atoms can be generalized as [19]

$\Xi=\sum_{E} q_{A}^{N_{A}}(T) q_{B}^{N_{B}}(T) \exp \left(\frac{\mu_{A} N_{A}+\mu_{B} N_{B}-E}{k_{B} T}\right)$

Where $\mathrm{q}_{\mathrm{i}}^{\mathrm{N}_{\mathrm{i}}}$ are the partition functions of atoms ( $\mathrm{i}=\mathrm{A}$ or $\mathrm{B}$ ) associated with inner and vibrational degree of freedom. $\mathrm{q}_{\mathrm{i}}$ the same whether the atom $\mathrm{i}$ is located in the pure state or in alloy. $\mu_{\mathrm{A}}$ and $\mu_{\mathrm{B}}$ are the chemical potentials and $\mathrm{E}$ is the configurational energy, $\mathrm{k}_{\mathrm{B}}$ the Boltzmann constant and $\mathrm{T}$, absolute temperature. The standard thermodynamical relation for free energy of mixing is

$$
\mathrm{G}_{\mathrm{M}}=\mathrm{G}_{\mathrm{M}}^{\mathrm{XS}}+\mathrm{Nk}_{\mathrm{B}} \mathrm{T}[\mathrm{CInC}+(1-\mathrm{C}) \operatorname{In}(1-\mathrm{C})]
$$

Where $\mathrm{C}$ is the concentration of the component $\mathrm{A}$. But excess of free energy of mixing [19] is

$\frac{\mathrm{G}_{\mathrm{M}}^{\mathrm{XS}}}{\mathrm{Nk}_{\mathrm{B}} \mathrm{T}}=\int_{0}^{\mathrm{C}} \ln \sigma^{\mathrm{Z}} \mathrm{dC}=\mathrm{C} \ln \gamma_{\mathrm{A}}+(1-\mathrm{C}) \ln \gamma_{\mathrm{B}}$

Where $\sigma=(\beta+2 \mathrm{C}-1) \exp \left(-\mathrm{w} / \mathrm{zk}_{\mathrm{B}} \mathrm{T}\right) / 2 \mathrm{C} \ldots . .3(\mathrm{a})$

$$
\begin{aligned}
& \gamma_{A}=[(\beta-1+2 C) / C(1+\beta)]^{z / 2} \ldots \ldots .3(b) \\
& \gamma_{B}=[(\beta+1-2 C) /(1-C)(1+\beta)]^{-/ 2} \ldots \ldots .3(c)
\end{aligned}
$$

$\beta=\left\{1+4 \mathrm{C}(1-\mathrm{C})\left[\exp \left(2 \mathrm{w} / \mathrm{zk}_{\mathrm{B}} \mathrm{T}\right)-1\right]\right\}^{1 / 2}$

For the equiatomic composition $\left(\mathrm{C}=\frac{1}{2}\right)$, relation (3) reduces to

$\frac{\mathrm{G}_{\mathrm{M}}^{\mathrm{X}}}{\mathrm{N}_{\mathrm{B}} \mathrm{T}}=\mathrm{h} 2^{\mathrm{z} / 2}\left[1+\exp \left(-\mathrm{w} / \mathrm{k}_{\mathrm{B}} \mathrm{T}\right]^{-\mathrm{z} / 2}\right.$
Using the relations (2) and (3), the free energy of mixing [20] will be

$$
\mathrm{G}_{\mathrm{M}}=\mathrm{Nk}_{\mathrm{B}} \mathrm{T}\left[\mathrm{C}(1-\mathrm{C}) \frac{\mathrm{w}}{\mathrm{k}_{\mathrm{B}} \mathrm{T}}+\mathrm{C} \ln \mathrm{C}+(1-\mathrm{C}) \ln (1-\mathrm{C})\right]
$$

Concentration fluctuations in the long-wavelength $\operatorname{limit}\left(\mathrm{S}_{\mathrm{cc}}(0)\right)$ hasemerged as an importantmicroscopic function to understand alloying behavior of liquid binary alloys. $\mathrm{S}_{\mathrm{cc}}(0)$ is thermodynamically related to free energy of mixing $\left(\mathrm{G}_{\mathrm{M}}\right)$ and activity $\left(\mathrm{a}_{\mathrm{i}}\right)[12]$. It is given as

$$
\begin{aligned}
\mathrm{S}_{\mathrm{cc}}(0)= & \mathrm{Nk}_{\mathrm{B}} \mathrm{T}\left(\frac{\partial^{2} \mathrm{G}_{\mathrm{M}}}{\partial \mathrm{C}^{2}}\right)_{\mathrm{T}, \mathrm{P}, \mathrm{N}}^{-1} \\
& =(1-\mathrm{C}) \mathrm{a}_{\mathrm{A}}\left(\frac{\partial \mathrm{a}_{\mathrm{A}}}{\partial \mathrm{C}}\right)^{-1} \\
& =\mathrm{Ca}_{\mathrm{A}}\left(\frac{\partial \mathrm{a}_{\mathrm{B}}}{\partial(1-\mathrm{C})}\right)^{-1}
\end{aligned}
$$

Equations (5) and(9) gives the theoretical value of $\mathrm{S}_{\mathrm{cc}}(0)$

$S_{c c}(0)=C(1-C)\left[1+\frac{Z}{2 \beta}(1-\beta)\right]^{-1}=C(1-C)\left[1-C(1-C) \frac{2 W}{k_{B} T}\right]^{-1}$

The warren-Cowley $[28,29]$ short range order parameter $\left(\alpha_{1}\right)$, another important microscopic function is computed to quantify the degree of order in the molten alloys $\alpha_{1}$ can be evaluated theoretically[12]:

$\alpha_{1}=\frac{\beta-1}{\beta+1}=(\mathrm{S}-1) /[\mathrm{S}(\mathrm{z}-1)+1]$

with $\quad \mathrm{S}=\frac{\mathrm{S}_{\mathrm{cc}}(0)}{\mathrm{C}(1-\mathrm{C})}=\frac{\mathrm{S}_{\mathrm{cc}}(0)}{\mathrm{S}_{\mathrm{cc}}^{\mathrm{id}}(0)}$

where $\mathrm{z}$ is the coordination number, which is taken as 10 for our purposes.

\subsection{Surface properties:}

In the statistical formulation of Prasad et al $[30,31]$ binary liquid alloy is considered to have a layered structure near the surface with thermodynamic equilibrium existing between the species at the surface and in the bulk. The surface properties of liquid alloys are influenced by their bulk 
thermodynamic properties. The surface grand partition function is related to the surface tension $\tau$ by the expression [30,31 ]

$\Xi^{\mathrm{s}}=\exp \left(\frac{-\mathrm{S} \tau}{\mathrm{k}_{\mathrm{B}} \mathrm{T}}\right)=\exp \left(\frac{-\mathrm{N}^{\mathrm{s}} \tau \xi}{\mathrm{k}_{\mathrm{B}} \mathrm{T}}\right)$

where $\mathrm{S}$ is the surface area and $\xi$ is the mean area of the surface per atom and is defined as $\xi=\mathrm{S} / \mathrm{N}^{\mathrm{s}}$, and $\mathrm{N}^{\mathrm{s}}$ is the total number of atoms at the surface. $\mathrm{k}_{\mathrm{B}}$ is the Boltzmann constant.

Prasad et al[30,31] gave the expression for surface tension of the binary liquid alloys in terms of activity coefficient $\left(\gamma_{i}\right)$ of the alloy components and interchange energy parameter(w), at the given temperature $\mathrm{T}$ as

$$
\begin{aligned}
& \tau=\tau_{A}+\frac{k_{B} T}{\xi} \ln \frac{C^{S}}{C}-\frac{k_{B} T}{\xi} \ln \gamma_{A}+\frac{w}{\xi}\left[p\left(1-C^{s}\right)^{2}+q(1-C)^{2}\right] \\
& \tau=\tau_{B}+\frac{k_{B} T}{\xi} \ln \frac{\left(1-C^{s}\right)}{(1-C)}-\frac{k_{B} T}{\xi} \ln \gamma_{B}+\frac{w}{\xi}\left[p\left(C^{S}\right)^{2}+q(C)^{2}\right]
\end{aligned}
$$

Where $\tau_{\mathrm{A}}$ and $\tau_{\mathrm{B}}$ are the surface tension values for the pure components $\mathrm{A}$ and $\mathrm{B}$ respectively; $\gamma_{A}$ and $\gamma_{B}$ are the bulk activity coefficients of the alloy components; $\mathrm{C}$ and $\mathrm{C}^{\mathrm{s}}$ are the bulk and surface concentrations of component $\mathrm{A}$. In zeroth approximation [19], where distribution of constituent atoms is completely random, $\gamma_{\mathrm{A}}$ and $\gamma_{\mathrm{B}}$ are given as

$$
\begin{aligned}
\operatorname{In} \gamma_{A} & =(1-C)^{2} \frac{w}{k_{B} T} \ldots \ldots \ldots . .12(a) \\
\operatorname{In} \gamma_{B} & =C^{2} \frac{\mathrm{w}}{k_{B} T} \ldots \ldots \ldots . .12(b)
\end{aligned}
$$

Using equations [Eq.(11) to Eq. (12)] one obtains a pair of equations for the surface tension of the alloys $\tau$, as

$$
\begin{aligned}
& \tau=\tau_{A}+\frac{k_{B} T}{\xi} \ln \frac{C^{S}}{C}+\frac{w}{\xi}\left[p\left(1-C^{s}\right)^{2}+(q-1)(1-C)^{2}\right] \ldots \ldots . .13(a) \\
& \tau=\tau_{B}+\frac{k_{B} T}{\xi} \ln \frac{\left(1-C^{S}\right)}{(1-C)}+\frac{w}{\xi}\left[p\left(C^{s}\right)^{2}+(q-1)(C)^{2}\right] \ldots \ldots .13(b)
\end{aligned}
$$

where $\mathrm{p}$ and $\mathrm{q}$ are the surface coordination fractions, which are defined as the fraction of the total number of nearest neighbors made by atom within its own layer and that in the adjoining layer. For $p$ and $q$, the following relation is available [30-33].

$P+2 q=1$

For closed packed structure, $\mathrm{p}=0.5$ while $\mathrm{q}=0.25$ (in view of the disordered structure and relaxation effect of the surface layer $p$ and $q$ should be treated as parameters[30]).

The pair of Eqs.13(a) and 13(b) can be solved numerically to obtain $\mathrm{C}^{\mathrm{s}}$ as a function of C. Obviously the surface concentration depends upon the surface tension of the ith component in the pure $\operatorname{state}\left(\tau_{i}\right)$, surface area per atom $(\xi)$, order energy(w) and the coordination fractions(p and $q)$. This approach is useful because it can be used to investigate the dependence of surface composition on order energy and surface coordination.

The mean atomic surface area $\xi\left(=\mathrm{A} / \mathrm{N}^{\mathrm{s}}\right)$ is given as

$$
\xi=\sum \mathrm{C}_{\mathrm{i}} \xi_{\mathrm{i}} \quad(\mathrm{i}=\mathrm{A}, \mathrm{B})
$$

Where the atomic area of hypothetical surface for each component is given as[30]:

$\xi_{\mathrm{i}}=1.102\left(\Omega_{\mathrm{i}} / \mathrm{N}_{0}\right)^{2 / 3}$

where $\Omega_{\mathrm{i}}$ is the molar volume of the species $\mathrm{i}$ and $\mathrm{N}_{0}$ stands for Avogadro number.

\section{RESULT AND DISCUSSION 3.1.Microscopic properties}

The energy parameter used for the calculation for $\mathrm{K}-\mathrm{Na}$ liquid alloys at $384 \mathrm{~K}$ has been determined from experimental value of $\mathrm{G}_{\mathrm{M}}^{\mathbf{X}}$ [1] for equiatomic composition $(\mathrm{C}=1 / 2)$, using the equations (4) which is found as

$$
\frac{\mathrm{w}}{\mathrm{k}_{\mathrm{B}} \mathrm{T}}=0.989
$$

The positive value of energy parameter $\left(\frac{\mathrm{w}}{\mathrm{k}_{\mathrm{B}} \mathrm{T}}\right)$ suggests that there is higher tendency for like atoms to pair in the alloy which implies a homo- 
coordination system. However, the tendency of pairing is weak since energy parameter is small. We have observed that if energy parameters are supposed to be independent of temperature (dw/ $\mathrm{dT}=0$ ), then $\mathrm{S}_{\mathrm{M}}$ and $\mathrm{H}_{\mathrm{M}}$ so obtained are in poor agreement with experimental data. This suggests the importance of temperature dependence ordering energy,w.

We have used Eq.(7) to compute the $\mathrm{S}_{\mathrm{cc}}(0)$ for K-Na. Figure 1 shows a plot of the calculated and experimental values of $\mathrm{S}_{\mathrm{cc}}(0)$ along with the ideal values. The calculated values of $\mathrm{S}_{\mathrm{cc}}(0)$ are in good agreement with the experimental values of $\mathrm{S}_{\mathrm{cc}}(0)$. The result can be used to understand the nature of atomic order in binary liquid alloys. At a given composition if $\mathrm{S}_{\mathrm{cc}}(0)<\mathrm{S}_{\mathrm{cc}}^{\mathrm{id}}(0)$, ordering in liquid alloy is expected while $\mathrm{S}_{\mathrm{cc}}(0)>\mathrm{S}_{\mathrm{cc}}^{\text {id }}(0)$ gives the indication of tendency of segregation. In figure 1 , it is seen that $\mathrm{S}_{\mathrm{cc}}(0)>\mathrm{S}_{\mathrm{cc}}^{\mathrm{id}}(0)$, which shows that liquid alloys $\mathrm{K}-\mathrm{Na}$ at $384 \mathrm{~K}$ is of segregating in nature.

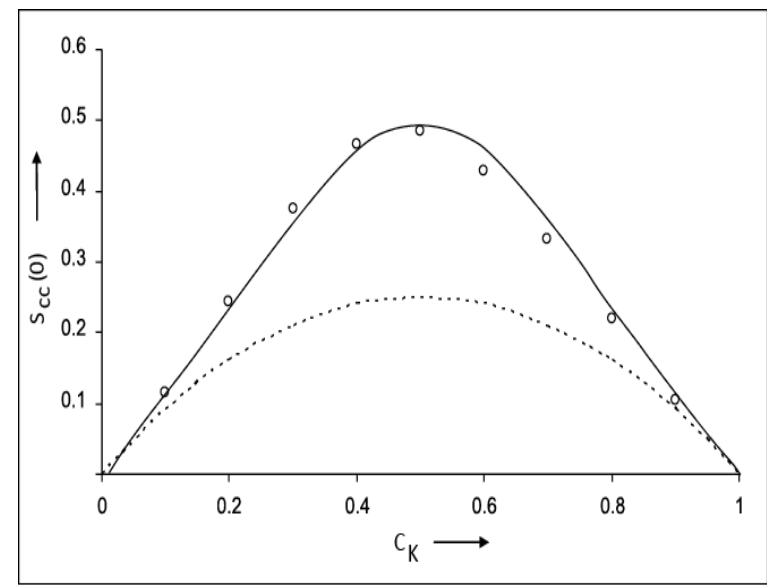

Fig. 1 : Concentration fluctuation at long wavelength limit ( $\mathrm{Scc}(0)) \mathrm{Vs}$ concentration of $\mathrm{K}\left(\mathrm{C}_{\mathrm{K}}\right)$ in liquid $\mathrm{K}-\mathrm{Na}$ alloy at $384 \mathrm{~K}$; solid lines for theoretical values, circles for experimental values[1] and dotted lines for ideal values.

Concentration fluctuation at long wavelength limit $\left(\mathrm{S}_{\mathrm{cc}}(0)\right)$ Vs concentration of $\mathrm{In}\left(\mathrm{C}_{\mathrm{K}}\right)$ in liquid $\mathrm{K}-\mathrm{Na}$ alloy at $384 \mathrm{~K}$; solid lines for theoretical values, circles for experimental values[1] and dotted lines for ideal values.

Short range order parameter $\left(\alpha_{1}\right)$ Vs concentration of $\operatorname{In}\left(\mathrm{C}_{\mathrm{K}}\right)$ in liquid $\mathrm{K}-\mathrm{Na}$ alloy at $384 \mathrm{~K}$.

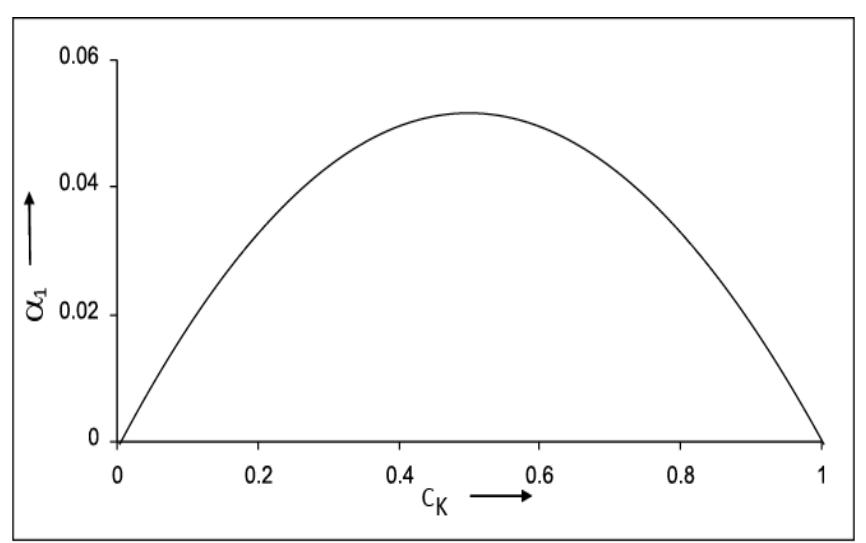

Fig.2 : Short range order parameter $\left(\alpha_{1}\right)$ Vs concentration of $\mathrm{K}\left(\mathrm{C}_{\mathrm{K}}\right)$ in liquid $\mathrm{K}-\mathrm{Na}$ alloy at $384 \mathrm{~K}$.

The knowledge of $\alpha_{1}$ provides an immediate insight into the nature of the local arrangement of atoms in the mixture. The minimum possible value of $\alpha_{1}$ is -1 and it indicates complete ordering of unlike atom pairing at nearest atoms. On the other hand the maximum value of $\alpha_{1}$ is +1 , which implies complete segregation leading to phase separation and $\alpha_{1}=0$ corresponds to a random distribution of atoms. Figure 2 shows the plots of $\alpha_{1}$ against chemical composition, obtained from Eq.(8) for $\mathrm{K}-\mathrm{Na}$ at $384 \mathrm{~K}$. It is observed that the plots are symmetrical about equiatomic composition and positive throughout the concentration range. The positive values of $\alpha_{1}$ (maximum at $\mathrm{C}_{\mathrm{Cu}}=0.5$ ) throughout whole concentration range of $\mathrm{K}(\mathrm{fig} .2)$ is the signatures of homo-coordination system in the $\mathrm{K}-\mathrm{Na}$ liquid alloys at $384 \mathrm{~K}$.

\subsection{Surface properties}

On the basis of approach of Prasad et al, the surface concentrations and surface tension of K-Na were computed numerically from the expressions in Eqs.13(a) and 13(b). For this, we need experimental data of density and surface tension of the components at the working temperature. We calculated the density and surface tension for the components $\mathrm{K}$ and $\mathrm{Na}[5,34]$ at the working temperature $384 \mathrm{~K}$ by using the equations as

$$
\begin{aligned}
& \rho(T)=\rho_{0}+\left(T-T_{0}\right) \frac{d \rho}{d T} \\
& \tau(T)=\tau_{0}+\left(T-T_{0}\right) \frac{d \tau}{d T}
\end{aligned}
$$


Where $\mathrm{T}$ and $\mathrm{T}_{0}$ are respectively the temperature of investigation and melting temperature; $\frac{\mathrm{d} \rho}{\mathrm{dT}}$ and $\frac{\mathrm{d} \tau}{\mathrm{dT}}$ represent the temperature coefficient of density and surface tension respectively for component metal of the alloys. The mean atomic surface area $\xi$ was calculated by using Eqs.(15) and (16). For calculating surface tension we used same estimated energy parameter, w. At first, surface concentrations of copper in alloy K-Na have been obtained as a function of bulk concentration by concurrently solving the equations 13(a) and 13(b). Using the obtained values of surface concentrations we computed the surface tension of K-Na liquid alloys at temperature $384 \mathrm{~K}$ for whole concentration range.

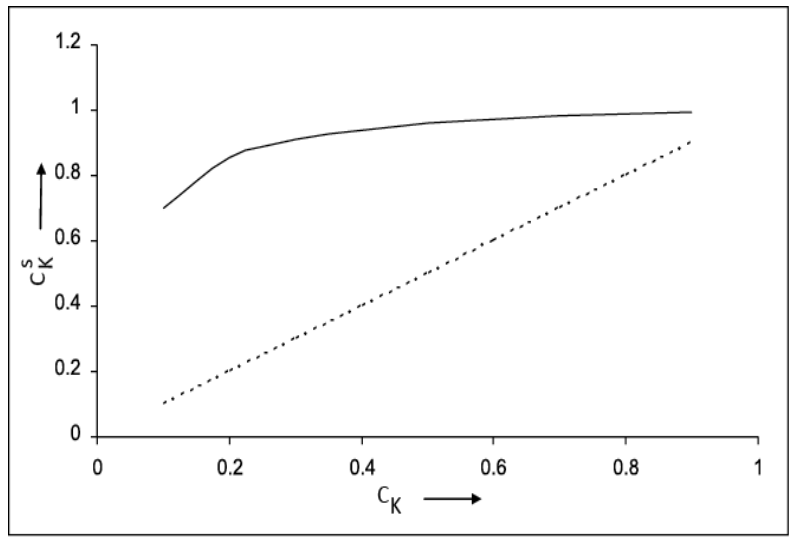

Fig.3 : Surface concentration of K (CKs ) Vs bulk concentration of K (CK ) in liquid K-Na alloy at 384K ; solid line for values from Prasad's approach and dotted line for ideal values.

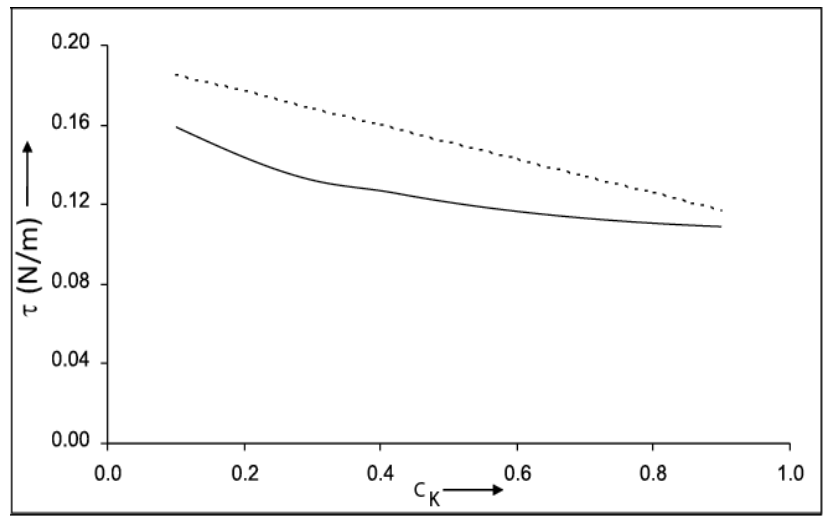

Fig.4 : Surface tension ( $\tau$ ) Vs bulk concentration of K (CK ) in liquid K-Na alloy at $384 \mathrm{~K}$; solid line for values from

Prasad's approach and dashed line for ideal values.

Surface concentration of $\mathrm{K}\left(\mathrm{C}_{\mathrm{K}}^{\mathrm{s}}\right) \mathrm{Vs}$ bulk concentration of $\mathrm{K}\left(\mathrm{C}_{\mathrm{K}}\right)$ in liquid $\mathrm{K}-\mathrm{Na}$ alloy at $384 \mathrm{~K}$; solid line for values from Prasad's approach and dotted line for ideal values.

Surface tension $(\tau)$ ) Vs bulk concentration of In $\left(\mathrm{C}_{\mathrm{K}}\right)$ in liquid $\mathrm{K}-\mathrm{Na}$ alloy at $384 \mathrm{~K}$; solid line for values from Prasad's approach and dotted line for ideal values.

The analysis gives that the computed surface tension for K-Na alloys at $384 \mathrm{~K}$ is less than ideal values at all concentration of potassium; i.e. there is negative departure of surface tension from ideality. Theoretical approach predicts that there is inverse relation between the surface tension and bulk concentration of potassium part in K-Na alloy [Fig.4]. But it is noticed that the surface concentration of potassium in $\mathrm{K}-\mathrm{Na}$ alloys is found to increase with the increase of bulk concentration of K [Fig.3]. This is an indication that in the alloys there are more atoms of component with bigger atom at the surface. Hence, at the surface of $\mathrm{K}-\mathrm{Na}$, K-atoms segregate at the surface in preference to $\mathrm{Na}$-atoms throughout the entire composition.

\section{Conclusions}

The theoretical analysis suggests that this alloys is of a weakly interacting nature. The analysis reveals that there is a tendency of like atom pairing or homo-coordination (K-K, Na-Na) in liquid $\mathrm{K}-\mathrm{Na}$ alloys at all concentrations. The ordering energy is found to be temperature dependent. With regards to surface tension, theoretical study shows that metal with lower surface tension tends to segregate on the surface of molten alloys. In K-Na system at 384K, the surface tension of K-Na alloys always smaller than ideal values, decreases with the increase of bulk concentrations of potassium, $\mathrm{K}$ atoms segregate to the surface at all bulk concentrations of potassium.

\section{ACKNOWLEDGEMENT}

We acknowledge to Prof. Dr. L.N. Jha (Chief, central department of physics, Tribhuvan University,Nepal) for fruitful suggestions and inspiring discussions. 


\section{REFERENCES}

[1] Hultgren, R., Desai, P.D., Hawkins, D.T., Gleiser, M. and Kelley,K.K.1973. Selected values of the thermodynamic properties of binaryalloys. A. S. M., Ohio.

[2] Saboungi, M.L., Marr, J. and Blander, M. 1978. J. Chem. Phys. 68:1375.

[3] Harada, S., Takahashi, S., Takeda, S., Tamaki, S., Grey P. andCusack, N.E. 1988. J. Phys. F18: 559.

[4] Lamparter, P., Martin, W. and Steeb, S.J. 1984. Non-cryst Solids, 61\& 62,p. 279.

[5] T.Iida and R.I.L.Guthrie,The physical properties of liquid metals(Clarendon Press,Oxford, 1988)

[6] J. Flory, J. Chem. Phys. 10 (1942) 51

[7] Harrision,W.A.1966.Pseudopotential in the Theory of metal,W.A.Benjamin,Inc.,New York

[8] J. L. Lebowitz, Phys. Rev., 1964, AL 33, 895

[9] T. E. Faber, Introduction to the theory of liquid metals. Cambridge Univ. Press,Cambridge, 1972

[10] M. Shimoji, Liquid metals. London Acad., London, 1977

[11] H. C. Longuet-Higgins, Proc. Roy. Soc., 1951, A 205, 247

[12] A. B. Bhatia, W. H. Hargrove and N. H. March, J. Phys., 1973, C 6, 621

[13] J. A. Alonso and N. H. March, Physica, 1982, B 114, 67

[14] B. Bernu, J. P. Hansen, Y. Hiwatari and G. Pastore, Phys. Rev., 1987, A 36, 4891

[15] W. Li and M. P. Tosi, Il Nuovo Cim., 1989, 11, 1509
[16] R.N. Singh,I K Mishra, Phys.Chem. Liq., 18((1988)303

[17] R.N. Singh ,Can.J.Phys.,34(1987)249

[18] R.N. Singh, I.S. Jha and S.K. Singh, J. Phys. Condens Matter, 3 (1993) 2787

[19] R.N. Singh,I K Mishra and V N Singh, J. Phys.Condens.Matter,2((1990)8457

[20] E.A.Guggenheim,Mixture,Oxford University Press,London(1952)

[21] R.P.Koirala, B.P.Singh, I.S.Jha and D.Adhikari, J.Molecular Liquids 179(2013)60

[22] A.Kumar,I.S.Jha and B.P.Singh, Physica B 406 (2011) 4338

[23] I. Koirala, I.S. Jha, B.P.Singh and D.Adhikari, Physica B, 423 (2013) 49

[24] I. Koirala, B.P.Singh, I.S.Jha, BIBECHANA 9 (2013) 130

[25] B.C.Anusionwu,Physica B,311(2002)272

[26] B.C.Anusionwu,O.Akinlade and L.A.Hussain, J.Alloys compounds 278 (1998) 175

[27] B.P. Singh ,D. Adhikari, I.S. Jha., Adv.Mat. Lett.2012,3(3),226-230

[28] B.E.Warren, X-ray Diffraction, Reading MA: Addison-Wesley, (1969)227

[29] J.M. Cowley, Phys. Rev. 77 (1950) 667

[30] L.C.Prasad,RN.Singh,V.N.Singh and G.P. Singh, J.Phys. Chem. B102 (1998) 921

[31] L.C.Prasad, R.N.Singh, Phys.Rev.B 44 (1991) 13768

[32] R.Novakovic,J.Non-Cryst.Solids, 356 (2010) 1593

[33] R.Novakovic, D.Giuranno, E.Ricci and A.Passerone, Surface Sci.576 (2005) 175

[34] E.A. Brandes, Smithells Metals Reference Book, Sixth Edition, (1983), Sec.14-6 